\title{
Nitric Oxide Is Formed \\ in Medicago truncatula-Sinorhizobium meliloti Functional Nodules
}

\author{
Emmanuel Baudouin, Laurent Pieuchot, Gilbert Engler, Nicolas Pauly, and Alain Puppo \\ Interactions Plantes-Microorganismes et Santé Végétale, UMR INRA 1064/Université de Nice-Sophia Antipolis/CNRS 6192, \\ 400, route des Chappes, BP 167, 06903 Sophia-Antipolis, France
}

Submitted 30 January 2006. Accepted 3 April 2006.

\begin{abstract}
Nitric oxide (NO) has recently gained interest as a major signaling molecule during plant development and response to environmental cues. Its role is particularly crucial for plant-pathogen interactions, during which it participates in the control of plant defense response and resistance. Indication for the presence of NO during symbiotic interactions has also been reported. Here, we defined when and where NO is produced during Medicago truncatula-Sinorhizobium meliloti symbiosis. Using the NO-specific fluorescent probe 4,5-diaminofluorescein diacetate, NO production was detected by confocal microscopy in functional nodules. NO production was localized in the bacteroid-containing cells of the nodule fixation zone. The infection of Medicago roots with bacterial strains impaired in nitrogenase or nitrite reductase activities lead to the formation of nodules with an unaffected NO level, indicating that neither nitrogen fixation nor denitrification pathways are required for NO production. On the other hand, the NO synthase inhibitor $\mathrm{N}$-methyl-L-arginine impaired NO detection, suggesting that a NO synthase may participate to NO production in nodules. These data indicate that a NO production occurs in functional nodules. The location of such a production in fully metabolically active cells raises the hypothesis of a new function for NO during this interaction unrelated to defense and cell-death activation.
\end{abstract}

Nitric oxide (NO) is a gaseous bioactive molecule that has been established during the last decades as a major signal in animals (Mayer and Hemmens 1997). More recently, its importance in plants emerged from pioneering works on plant responses to pathogens (Delledonne et al. 1998; Durner et al. 1998). Our current knowledge of NO function during plantpathogen interactions has recently been reviewed (Delledonne 2005; Wendehenne et al. 2004). NO is rapidly produced during the incompatible interactions with biotrophic pathogens but is also accumulated during compatible interactions with necrotrophic pathogens or in response to basal elicitors of plant responses such as lipopolysaccharides (Delledonne et al. 1998; Van Baarlen et al. 2004; Zeidler et al. 2004). In these contexts, NO production is generally associated with plant cell death and hypersensitive response. NO is also involved in the induction of defense genes, such as pathogenesis-related $1(P R 1)$ gene and phenylalanine ammonia lyase (Durner et al. 1998). In addition to its involvement in biotic stress responses, NO is a key compo-

Corresponding author: Emmanuel Baudouin: E-mail: baudouin@unice.fr; Telephone: +33-4-92-38-66-38; Fax: +33-4-92-38-66-40. nent of the signaling cascades activated in response to several abiotic stresses. In guard cells, NO, which is generated in response to abscissic acid production, participates in the control of stomatal closure, a classical response of plants to drought (Desikan et al. 2002). A large increase of NO concentration has also been observed in roots subjected to hypoxia, and a correlation between plant response to low oxygen and NO production has been proposed (Dordas et al. 2003a). NO functions are not restricted to stress responses but encompass the whole lifespan of the plant. Indeed, the formation of adventitious roots induced by auxins, the lignification of vascular tissues, and the control of plant flowering time rely on NO production (Correa-Aragunde et al. 2004; Gabaldon et al. 2005; He et al. 2004). NO also participates in iron homeostasis by inducing the iron-storage protein ferritin gene in response to iron (Murgia et al. 2002). This ubiquitous involvement of $\mathrm{NO}$ in plant physiology regulation makes it one of the pivotal messengers of signaling networks.

Recent studies have shed light on how NO turnover may function in plants. A nonenzymatic production of NO from nitrite in the apoplast has been reported (Bethke et al. 2004). Nevertheless, attention has focused on enzymatic sources of NO (Crawford and Guo 2005). It is now obvious that several enzymatic processes operate independently or synergistically to produce NO during plant development or response to stresses. Nitrate reductase activity participates in NO production during abscissic acid-induced stomatal closure, although it may not directly produce NO but, rather, may provide nitrite to an unknown enzyme responsible for $\mathrm{NO}$ accumulation (Desikan et al. 2002; Planchet et al. 2005). In contrast to nitrite-based NO production, NO synthases (NOS) produce NO and citrulline from arginine, $\mathrm{O}_{2}$, and NADPH. NOS activities sensitive to mammalian NOS inhibitors have been measured in several plant species (Neill et al. 2003). Nevertheless, it is only recently that a gene coding for a functional NOS has been isolated in Arabidopsis thaliana (Guo et al. 2003). The characterization of the AtNOS1 knock-out mutant shows that AtNOS1 participates in NO production during development and also during plant responses to biotic and abiotic stresses (Zeidler et al. 2004). Due to its pleiotropic effects, NO detoxification is also a critical aspect of its bioactivity. In this respect, nonsymbiotic plant haemoglobins efficiently detoxify NO to nitrate, and the expression of such haemoglobins is directly associated with abiotic and biotic stress responses (Perazzolli et al. 2004).

Contrary to that in pathogenic situations, the interaction between legumes and soil bacteria of the Rhizobiaceae family leads to the establishment of a symbiotic relationship characterized by the formation of new differentiated organs called nodules, which provide a niche for bacterial nitrogen fixation. 
Functional nodules result from the combination of developmental and infectious processes that ensure organ formation on one hand and enable the bacteria to reach nodule cells via infection threads on the other hand. Finally, bacteria released in plant cells undergo a differentiation program and become bacteroids with the unique ability to fix atmospheric nitrogen via the nitrogenase activity. Indications of the possible occurrence of NO during legume-rhizobia interactions have been reported. A NOS-like activity has been measured in lupine nodules (Cueto et al. 1996). Moreover, NO complexed to leghemoglobin (Lb), the hemoprotein ensuring $\mathrm{O}_{2}$ fluxes to bacteroids, has been detected in soybean nodules by electron paramagnetic resonance (Mathieu et al. 1998). Nevertheless, these data did not reveal where and when NO may be produced during symbiotic interactions. Using the Medicago truncatula-Sinorhizobium meliloti symbiotic model, we provide evidence that NO is formed in functioning nodules and that this production occurs in bacteroid-containing cells.

\section{RESULTS}

In order to gain a precise view of the spatio-temporal fluctuations of NO production during $M$. truncatula-S. meliloti interaction, the presence of NO in root tissues of inoculated plants was analyzed, using the cell-permeable NO-specific probe 4,5-diaminofluorescein diacetate (DAF-2DA), which is converted to its fluorescent triazole derivative DAF-2T upon reaction with NO (Nakatsubo et al. 1998). The formation of DAF-2T was visualized in intact roots by confocal laser microscopy. As previously reported by others (Guo et al. 2003), root tips appeared strongly fluorescent in relation to NO production in these tissues, which indicated that our experimental procedure is suitable for NO detection in $M$. truncatula roots. Following infection, characteristic deformations of root hairs were observed 12 to $48 \mathrm{~h}$ postinoculation, followed by the formation of infection threads. Nevertheless, we did not observe a specific NO-related fluorescence associated with these specific morphological changes. Similarly, NO was not detected in the emerging nodules. The absence of NO production was also evidenced by electron paramagnetic resonance, as no NO-related adduct was detected in response to nodulation factors and bacterial infection. Although a transient and discrete production of NO cannot be ruled out, these observations strongly suggest that $\mathrm{NO}$ is not produced during the early stages of symbiosis establishment.

As nodule thickness did not allow an efficient penetration of the DAF-2DA probe and subsequent observation of the nodule inner tissues, we performed NO detection on fresh nodule slices. As shown in Figure 1B, a significant fluorescent signal was observed in young (10 days postinoculation) nodules. This signal did not correspond to auto-fluorescence, as it was not observed in the absence of DAF-2DA. This result was confirmed by treating nodule slices with the NO scavenger 2-(4carboxyphenyl)-4,4,5,5-tetramethyl imidazoline-1-oxyl-3-oxide (cPTIO). Indeed, cPTIO treatment extinguished the fluorescence and further established that the fluorescence was representative of NO production (Fig. 1D). In addition, the fluorescence presented a localized pattern, which ruled out the possibility of a general stress response induced by wounding. The observation of older (20 and 30 days postinoculation) nodules showed that NO detection was associated with the nodule fixation zone and was not observed in meristematic, infection, and senescence zones (Fig. 1F and $\mathrm{H}$ ). Moreover, only a subset of cells appeared fluorescent. To rule out the hypothesis that this fluorescence patterning was a consequence of a heterogeneous distribution of DAF-2DA within nodule tissues, nodule slices were exposed to a NO burst by treatment with the short-life NO-releasing compound methyl-2-hydroxymino-5-nitro-6-methoxy-3-hexena- mide (NOR-1). As illustrated in Figure 1J, NOR-1-treated nodules exhibited a homogeneous fluorescence, indicating that DAF-2DA was equally distributed in nodule tissues. Taken together, these data pointed out that a subset of cells from the fixation zone was specifically producing NO in symbiotic nodules.

We could further observe that the labeled cells were bigger than the nonlabeled ones. It is well known that not all the cells of the fixing zone contain bacteroids and that bacteroid-containing cells appear bigger than the noninfected ones. Therefore, we analyzed the possible relationship between cell infection and NO production. We used a fluorescent nucleic acid dye of the Syto family, which has been previously reported as being efficient for bacteroid detection in nodules (Haynes et al. 2004). In regard to the spectral characteristics of the different Syto molecules, we chose the Syto 83 dye, the fluorescent emission of which can be fully discriminated from the DAF-2T fluorescent emission. Nodule slices were cotreated with Syto83 and DAF-2DA dyes and were subsequently observed by confocal microscopy. As shown in Figure 2A, Syto83 only stained a fraction of cells, and a strong correlation between the cells that contained bacteroids and the cells that were producing NO was observed (Fig. 2B). Nevertheless, it should be noted that a minor fraction of the bacteroid-containing cells did not exhibit NO-related fluorescence, which may be related to different metabolic states of those plant cells, bacteroids, or both. These observations further evidence that NO production is directly or indirectly the consequence of the presence of bacteroids in the plant cells.

The specific location of NO detection in nodules pointed out that there may be a relation between nitrogen fixation and nitricoxide production. To address this question, we analyzed NO production in nodules derived from root infection with a $S$. meliloti nifH mutant deficient in nitrogenase activity. The nodules formed display a reduced and nonfunctional fixation zone (Hirsch et al. 1983). As illustrated in Figure 3D, such nodules presented a NO production comparable to control nodules (Fig. 3B). These data indicate that nitrogen-fixation activity is neither responsible nor required for $\mathrm{NO}$ production.

In order to circumvent the sources involved in NO production in nodules, we first evaluated the possible participation of the bacterial denitrification pathway. Indeed, denitrification is known to generate $\mathrm{NO}$ as an intermediate of $\mathrm{NO}_{3}{ }^{-}$reduction to $\mathrm{N}_{2}$ in denitrifying bacteria such as Sinorhizobium meliloti. In this pathway, $\mathrm{NO}$ is formed by nitrite reductase from $\mathrm{NO}_{2}^{-}$and is converted to $\mathrm{N}_{2} \mathrm{O}$ by nitric oxide reductase. We studied the level of NO in nodules formed upon root infection with $S$. meliloti nirK and norD mutant strains, impaired in nitrite reductase and nitric oxide reductase activity, respectively. As illustrated in Figure 3F and $\mathrm{H}$, the infection by nirK or norD mutant strains did not significantly affect NO production, suggesting that denitrification is not a major source of NO in nodules.

A major source of $\mathrm{NO}$ in eukaryotes and some prokaryotes is the activity of NOS, which generate NO and L-citrulline from L-arginine. To analyze whether a NOS-like enzyme may participate in NO production in plant nodules, we pretreated nodule slices with $N$-methyl-L-arginine (L-NMMA), a competitive NOS inhibitor, before NO detection with DAF-2DA. As shown in Figure 4B, L-NMMA pretreatment led to a drastic reduction of NO detection. On the other hand, its biologically inactive analog D-NMMA did not affect NO detection (Fig. 4D). These data suggest that a NOS-like enzyme may be responsible for NO production in nodule infected cells.

\section{DISCUSSION}

Symbiotic interactions between legumes and rhizobia represent an original physiological context that results from a com- 
bination of developmental and infectious events. The importance of NO during the interaction of plants with pathogens brought us to characterize the occurrence of this molecule during the infection of the model legume $M$. truncatula by its bacterial partner $S$. meliloti. Although the methodology used allows the detection of NO concentration as low as $5 \mathrm{nM}$ (Nakatsubo et al. 1998), we did not detect NO production in our system before the occurrence of nodules. The production of NO in Lotus japonicus roots infected with Mesorhizobium loti was recently reported (Shimoda et al. 2005). Such production was observed at an early timepoint ( $4 \mathrm{~h}$ postinfection), preceding those of our analysis (12 to $48 \mathrm{~h}$ ). Thus, it may reflect that NO is evoked transiently during the very first hours of infection. Lohar and associates (2006) evidenced similar rapid and transient activation patterns for defense/stress genes, which are strongly up-regulated after $1 \mathrm{~h}$ and get repressed $6 \mathrm{~h}$ postinoculation.

In contrast to the early steps of the interaction, we observed a significant production of NO in functional nodules. Strikingly, NO detection was associated with the fixation zone of the nodule, in which a subset of plant cells is filled with bacteroids actively fixing atmospheric nitrogen. These observations directly evidence the production of NO that was previously hypothesized, based on the presence of nitrosylleghemoglobin (LbNO)
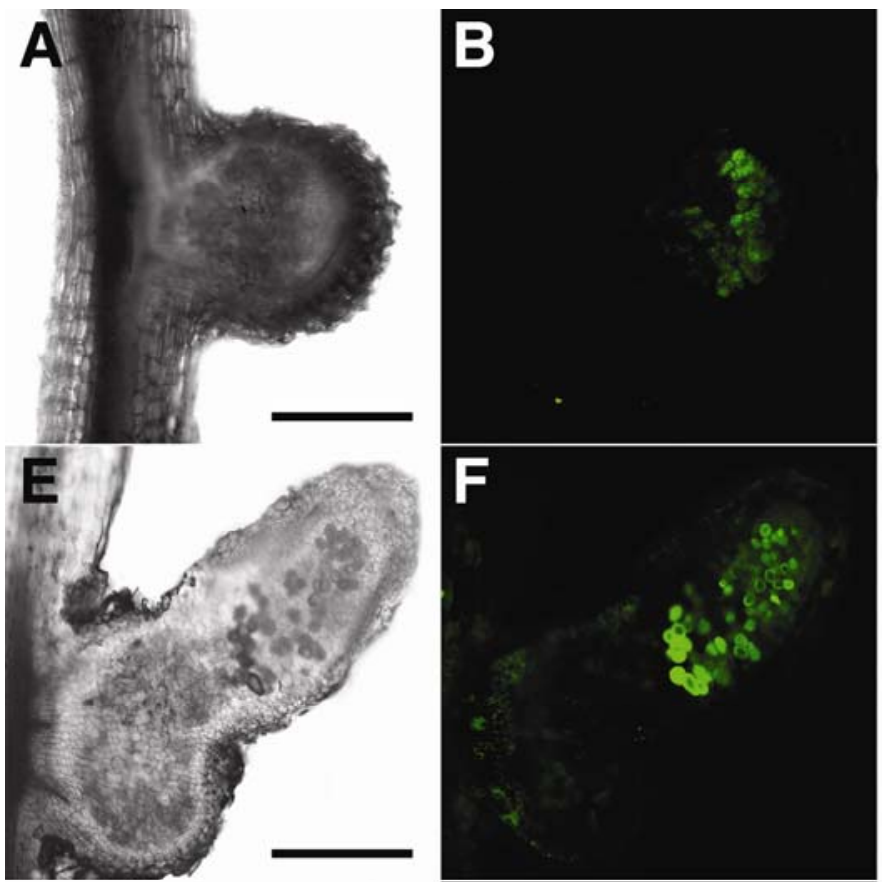

C
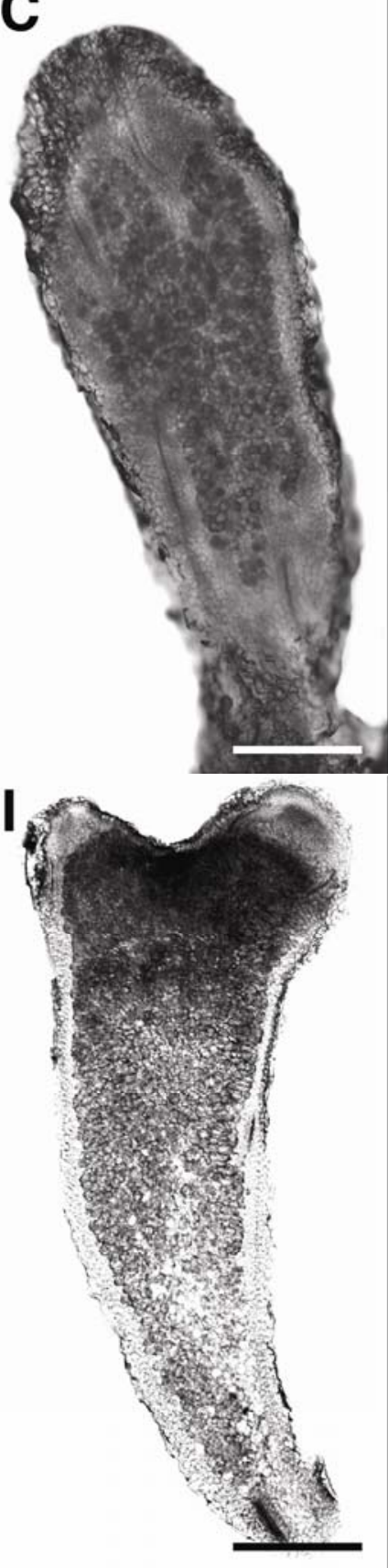
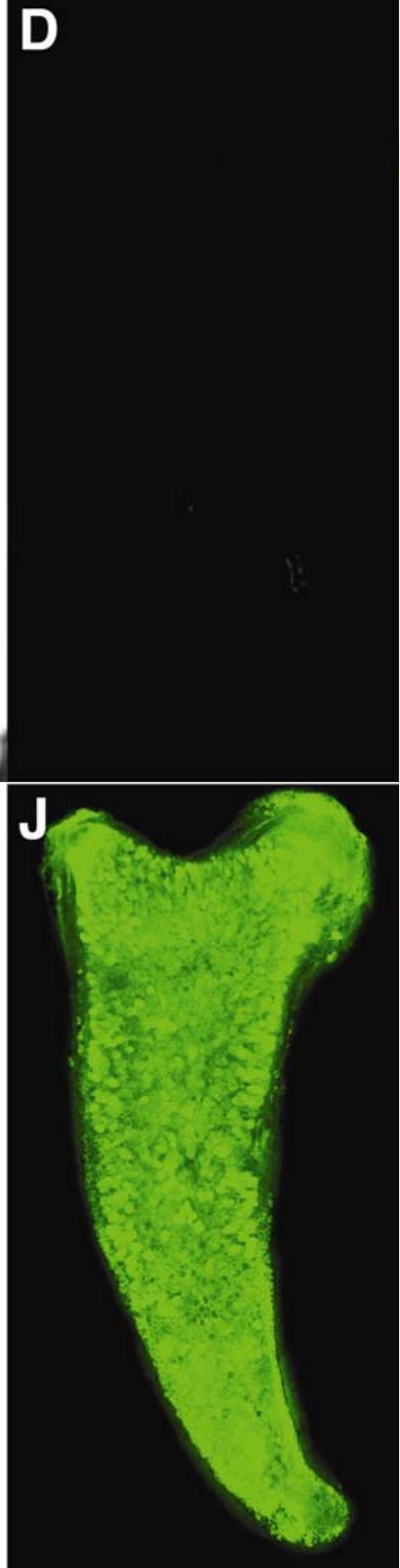

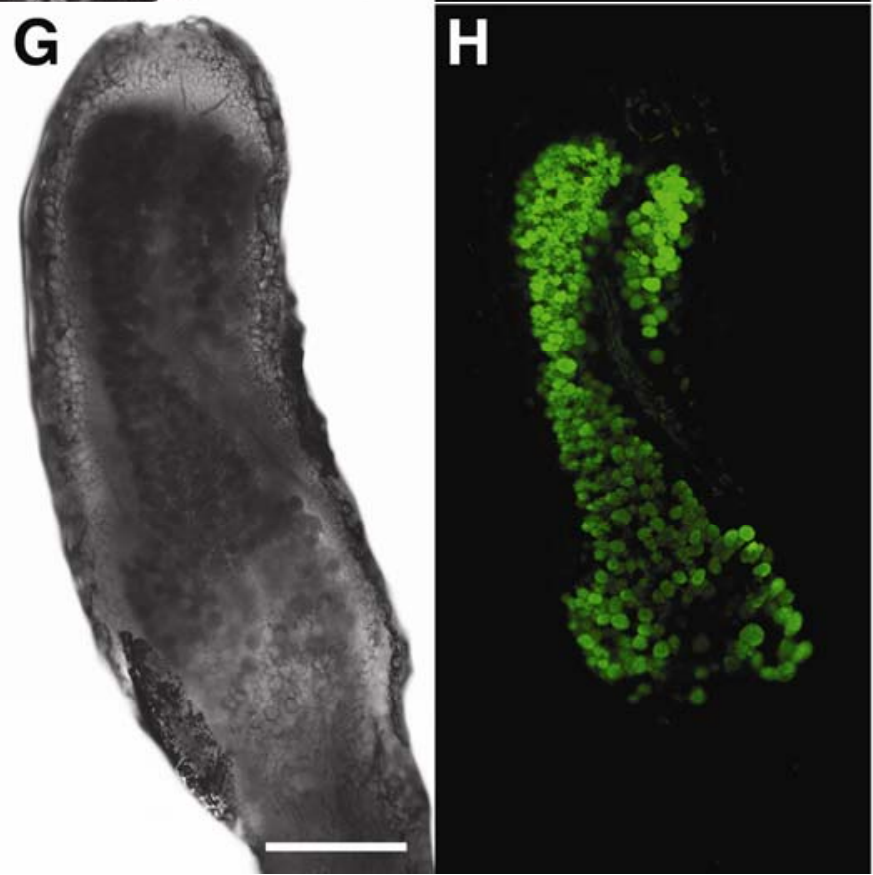

Fig. 1. Detection of nitric oxide (NO) production in Medicago root nodules. A, C, E, G, and I, Light and B, D, F, H, and J, fluorescence micrographs of 4,5diaminofluorescein diacetate (DAF-2DA)-treated nodule sections $(150 \mu \mathrm{m})$. Nodules slices were obtained 10 days (A, B), 20 days (E, F), or 30 days $(\mathrm{C}, \mathrm{D}$, G, H, I, J) after bacterial inoculation. DAF-2DA fluorescent triazole derivative fluorescence was observed following preincubation with the NO scavenger 2(4-carboxyphenyl)-4,4,5,5-tetramethyl imidazoline-1-oxyl-3-oxide (1 mM, D) or the NO donor methyl-2-hydroxymino-5-nitro-6-methoxy-3-hexenamide (1 $\mathrm{mM}, \mathrm{J})$ and was compared with the control $(\mathrm{H}) . \mathrm{Bar}=500 \mu \mathrm{m}$. 


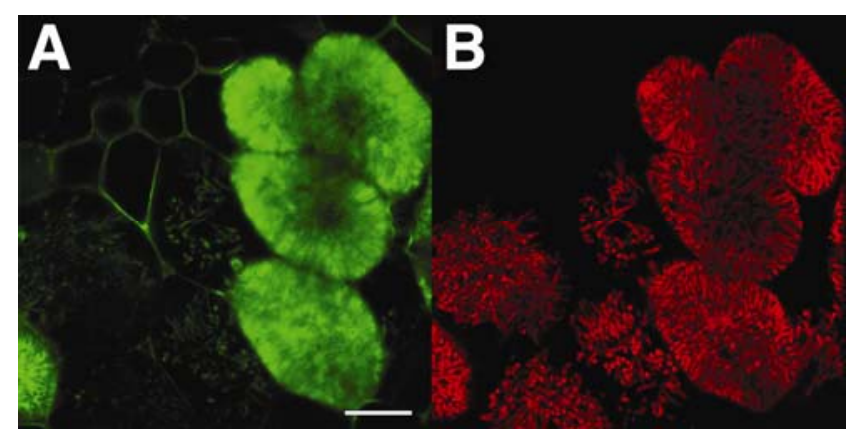

Fig. 2. Colocalization of nitric oxide $(\mathrm{NO})$ production and bacteroids in the nodule-fixing zone. Slices from 30-day-old nodules were incubated in the presence of $10 \mu \mathrm{M} 4,5$-diaminofluorescein diacetate and $1 \mu \mathrm{M}$ Syto83. The fluorescence associated with $\mathbf{A}$, NO detection and $\mathbf{B}$, bacteroids was observed by confocal laser microscopy. Bar $=30 \mu \mathrm{m}$.

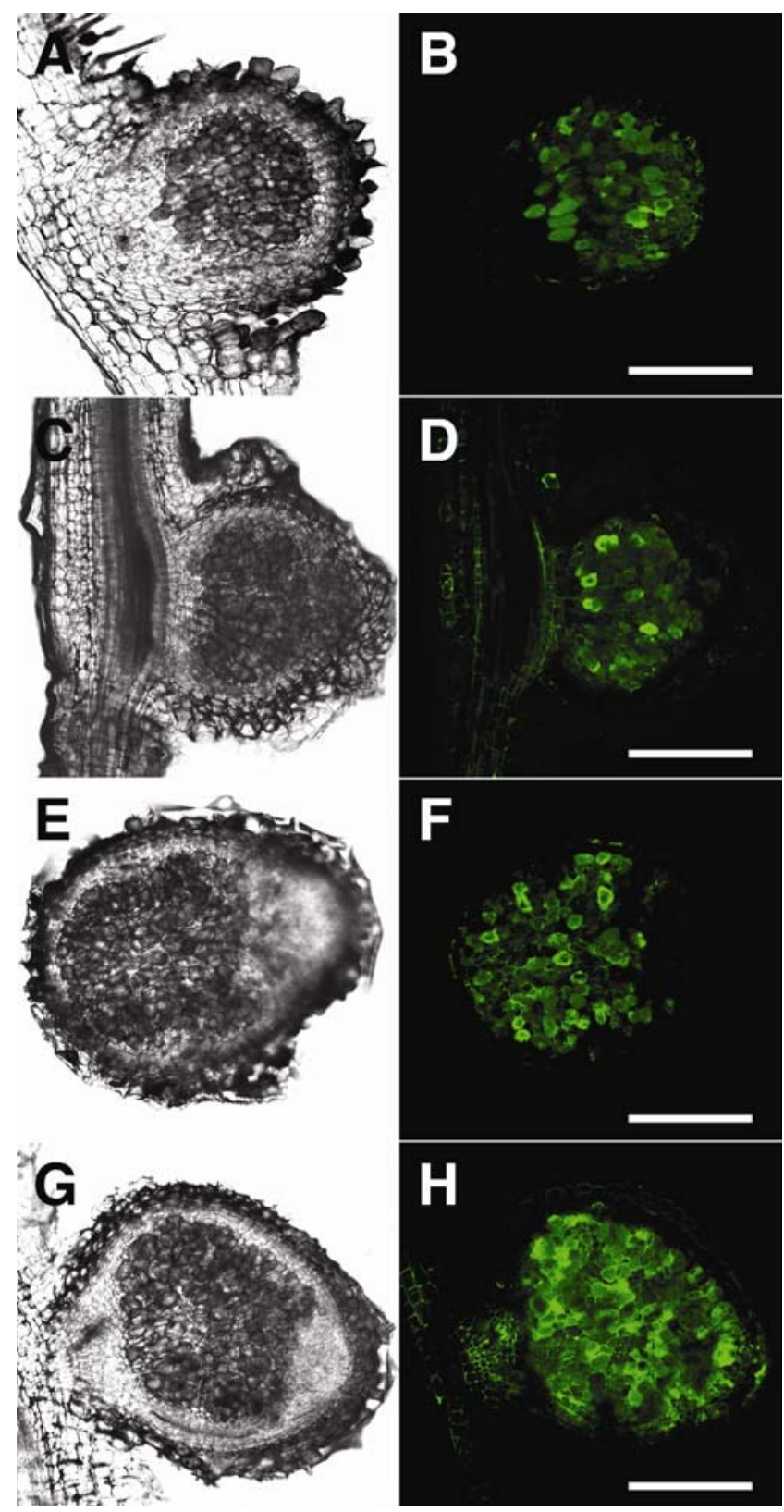

Fig. 3. Effect of bacterial mutations on nitric oxide production. A, C, E, and $\mathbf{G}$, Light and $\mathbf{B}, \mathbf{D}, \mathbf{F}$, and $\mathbf{H}$, fluorescence micrographs of 4,5-diaminofluorescein diacetate-treated nodule sections. Nodules slices were obtained 10 days after root infection with wild-type (A, B), nifH (C, D), nirK (E, F), and norD Sinorhizobium meliloti strains. Bar $=500 \mu \mathrm{m}$. complexes in functional soybean nodules (Mathieu et al. 1998). LbNO complex abundance declined with nodule aging and was undetectable in senescent nodules (Mathieu et al. 1998). From our observations, this decline is probably correlated with the progressive collapse of the fixing zone with nodule aging. Indeed, we show that the presence of bacteroids in plant cells is required for NO production, as evidenced by the colocalization of NO signal and bacteria in the cells. Nevertheless, the presence of bacteroids in cells is not sufficient per se for $\mathrm{NO}$ production, as some infected cells do not exhibit NOrelated fluorescence, suggesting that specific physiological conditions may be required for NO production. In this view, we found evidence that $\mathrm{NO}$ production does not require nitrogen fixation or bacterial denitrification. Indeed, the similar levels of NO detected in nodules formed upon infection with the $S$. meliloti nifH mutant strain impaired in nitrogenase activity clearly shows that nitrogen fixation is not required for NO production. On the other hand, a role for denitrification in NO production in nodules has been proposed, based on the induction of Bradyrhizobium japonicum denitrification genes in the symbiotic zone of soybean nodules (Mesa et al. 2004). Nevertheless, our data do not corroborate this hypothesis, as no significant reduction of NO production was observed in nodules formed upon infection with a $S$. meliloti strain, deficient in
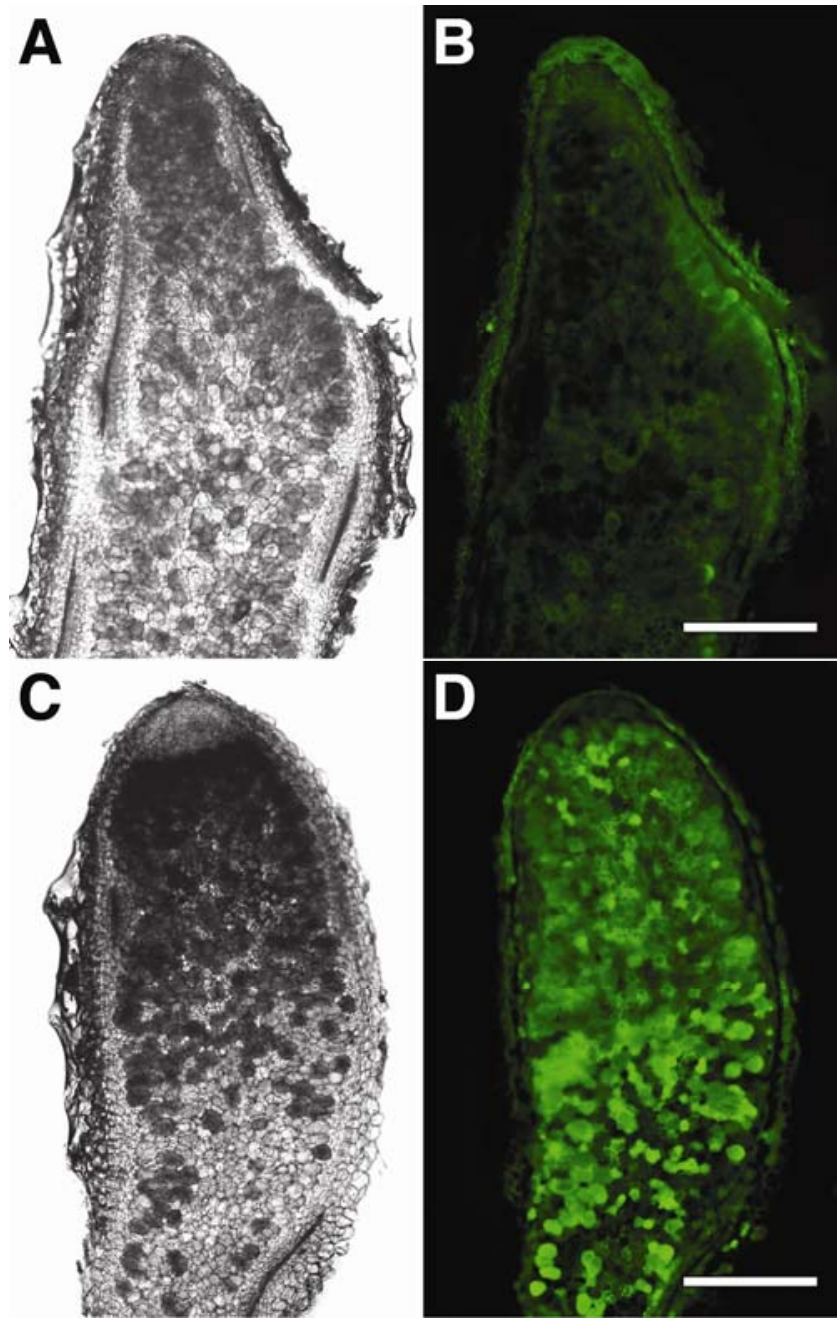

Fig. 4. Effect of a nitric oxide (NO) synthase inhibitor on nodule NO production. $\mathbf{A}$, and $\mathbf{C}$, Light and $\mathbf{B}$, and $\mathbf{D}$, fluorescence micrographs of 4,5diaminofluorescein diacetate-treated 30-day-old nodule sections preincubated with the NO synthase inhibitor L-NMMA $(1 \mu \mathrm{M}, \mathrm{B})$ or its biologically inactive analog D-NMMA (1 mM, D). Bar $=500 \mu \mathrm{m}$. 
nitrite reductase activity, that catalyzes the reduction of $\mathrm{NO}_{2}^{-}$ to NO. Therefore, although significant concentrations of $\mathrm{NO}_{2}^{-}$ have been detected in bacteroids, even in the absence of a $\mathrm{NO}_{3}{ }^{-}$supply (Becana et al. 1985), NO production would not be related to bacteroid denitrification activity. Even though the physiological significance of nodule denitrification processes remains elusive, NO may constitute an induction factor for denitrification gene expression. This function has been assessed in Agrobacterium tumefaciens, in which NO produced by the infected plant cells could induce, in the bacteria, the expression of reporter genes fused to nirK or nor promoters (Baek and Shapleigh 2005). Because Sinorhizobium meliloti is closely related to Agrobacterium tumefaciens, such cross-talk between plant and bacteria, using $\mathrm{NO}$ as a mediator, may also take place in nodule infected cells.

Although the source of NO production in nodules remains unclear, preliminary indications point out the possible implication of a NO synthase-like enzyme. We showed that the mammalian NOS inhibitor L-NMMA efficiently inhibited nodular NO production, whereas its biologically inactive analog, D-NMMA, did not interfere with NO production, suggesting that L-NMMA effect may indeed imply NOS inhibition. The involvement of a NOS-like enzyme in nodular NO formation is consistent with previous reports on the detection of a NOS-like activity in lupine nodules (Cueto et al. 1996). Furthermore, Cueto and collaborators (1996) localized NOS activity in nodule infected tissues. Although the possibility that a bacterial NOS inhibited by LNMMA sustains NO production in nodules cannot be ruled out, the absence in the genome of S. meliloti of any gene similar to the prokaryotic and eukaryotic NOS identified so far makes it unlikely. On the other hand, we recently cloned a $M$. truncatula gene encoding a putative NOS-like enzyme (N. Pauly, unpublished data). This gene presents high similarities with $A$. thaliana AtNOS1, which encodes a NO synthase responsible for NO production in diverse physiological situations (Guo et al. 2003). Further characterization will clarify the potential involvement of $M$. truncatula NOS in NO generation in nodules. Nevertheless, as L-NMMA inhibition was not complete, the hypothesis that another source participates in NO production should not be underestimated. If so, the nitrate reductase recently characterized in Lotus japonicus may constitute a possible candidate in regards of its specific and nitrate-independent expression in fixing nodules (Kato et al. 2003).

Our finding that nitrogen-fixing cells accumulate significant levels of NO raises the question of the possible function of this compound during symbiosis. Several proteins that are synthesized by the plant or the bacterial partner have a strong affinity for NO. This is especially true for Lb, which is the most abundant protein in fixing nodules. The ability of ferrous $\mathrm{Lb}$, which is the major form of $\mathrm{Lb}$ in vivo, to fix NO has been evidenced in vitro and in vivo (Harutyunyan et al. 1996). Due to its high affinity, one can speculate that a large part of the NO that is produced is rapidly bound by $\mathrm{Lb}$ to form $\mathrm{LbNO}$. To date, LbNO has been viewed as an unfunctional form of Lb, the formation of which impairs the optimum functioning of nitrogen fixation (Mathieu et al. 1998). Nevertheless, in regard to the function of human haemoglobin (Gow et al. 1999), it may also serve as a reservoir for bioactive NO. If such function is sustained by LbNO, it would shed light on a new unsuspected role for $\mathrm{Lb}$ during symbiosis. In addition to $\mathrm{Lb}$, FixL, the bacterial protein responsible for $\mathrm{O}_{2}$ sensing, can also readily fix $\mathrm{NO}$ alternatively to $\mathrm{O}_{2}$ (Gilles-Gonzalez and Gonzalez 2005). The consequences of NO fixation by FixL remain unclear, especially in terms of the activation of downstream signal transduction pathways. Mesa and coworkers (2003) pointed out that NO may function as a signal-activating bacterial response to the low oxygen concentrations occurring in the nitrogen-fixing tissues by regulating specific transcription factors such as NnrR, which controls denitrification gene expression. The hypothesis of NO being a microaerobiosis signal may well extend beyond the bacterial partner. Indeed, we isolated a series of genes related to plant response to hypoxia in a screen for $M$. truncatula genes induced upon NO treatment (unpublished data). On the other hand, a large scale analysis of gene expression in Lotus japonicus nodules evidenced a generalized upregulation of hypoxia-related genes in fixing nodules (Colebatch et al. 2004). In regard to its importance during plant response to hypoxia (Dordas et al. 2003b), NO may orchestrate, or at least participate in, the response of the symbiotic partners to $\mathrm{O}_{2}$ deprivation. Finally, the differentiation of bacteroid-containing nitrogen-fixing symbiotic cells involves endoreduplication cycles essential for proper nodule development and functioning (Vinardell et al. 2003). As NO was recently shown to interfere with cell cycles in plants (Otvos et al. 2005), it would be of interest to investigate its possible participation in the regulation of cell cycle in nodules.

\section{MATERIALS AND METHODS}

\section{Biological material growth conditions.}

Medicago truncatula cv. Jemalong seeds were scarified in 1 $\mathrm{M} \mathrm{H}_{2} \mathrm{SO}_{4}(8 \mathrm{~min})$, were sterilized in $2 \% 0 \mathrm{HgCl}_{2}(10 \mathrm{~min})$ and $6 \%$ bleach solution ( $4 \mathrm{~min}$ ), and were rinsed with sterile distilled water. Germination was carried out for two days on $0.4 \%$ agar plates in the dark. For short-term experiments (up to 10 days), seedlings were grown under sterile conditions in $10-\mathrm{cm}$ square petri dishes containing modified Fahreus medium (Boisson-Dernier et al. 2001). For long-term experiments, seedlings were transferred to sterile sand and were watered with nutritive solution in the absence of nitrogen supply. Plantlets were grown in a climatic chamber as described (Frendo et al. 1999) and were inoculated when 7 days old with wild-type Sinorhizobium meliloti 1021 (Sm1021) or different Sm1021 derivatives: Sm1021 NifH::Tn5 $\left(\mathrm{NifH}^{-}\right), \mathrm{Sm} 1021$ loe-7::Tn5 luxAB nirK::Tn1721 ( NirK $^{-}$), and Sm1021 loe-7::Tn5 luxAB norD::Tn1721 (NorD $\left.{ }^{-}\right)$. Root samples were collected 24, 48, 72 , and $96 \mathrm{~h}$ after inoculation, and nodules were collected 10 , 20 , and 30 days after inoculation and were immediately processed for NO labeling.

\section{Nitric oxide detection.}

Experiments were realized on young entire roots and fresh nodule slices $(150 \mu \mathrm{m})$ obtained with a vibratome 1000 Plus (Labonord, Templemars, France). Plant material was then incubated for $30 \mathrm{~min}$ in the dark in 100 to $500 \mu \mathrm{l}$ of detection buffer DB (10 mM Tris-HCl, pH 7.4, $10 \mathrm{mM} \mathrm{KCl)} \mathrm{containing}$ $10 \mu \mathrm{M}$ DAF-2DA (Sigma-Aldrich, Lyon, France). Plant tissues were subsequently washed for $30 \mathrm{~min}$ with $\mathrm{DB}$ and were mounted in DB for observation.

When cPTIO, L-NMMA and D-NMMA were used, plant tissues were preincubated for $30 \mathrm{~min}$ in DB containing $1 \mathrm{mM}$ of the inhibitor and, subsequently, were labeled with DAF-2DA and were washed with inhibitor-containing DB. When NOR-1 was used, plant tissues were loaded with DAF-2DA, were washed with $\mathrm{DB}$, and were treated with $1 \mathrm{mM}$ NOR-1-containing DB. Excess NOR-1 was eliminated before observation by washing with $\mathrm{DB}$.

The formation of DAF-2T following NO reaction with DAF2DA was visualized using a Zeiss LSM 500 confocal laser microscope (Carl Zeiss SA, Le Pecq, France) upon excitation at $488 \mathrm{~nm}$ with an Argon 2 laser. Dye emission was recorded using a 505 to $530 \mathrm{~nm}$ band-pass filter coupled with a $515-\mathrm{nm}$ long-pass filter. Images were processed and analyzed using the Zeiss LSM510 Meta software and Adobe Photoshop. 


\section{Bacteroid detection.}

Bacteroid detection was carried out together with NO detection on fresh nodule slices $(150 \mu \mathrm{m})$. The nucleic acid dye Syto83 (Invitrogen, Cergy Pontoise, France) was added to DB containing DAF-2DA at a final concentration of $1 \mu \mathrm{M}$, and plant material was processed as for NO detection. Syto83 emission was recorded using a 560 to 615 band-pass filter upon excitation at $543 \mathrm{~nm}$ with a helium laser.

\section{ACKNOWLEDGMENTS}

This work was supported by an Action Concertée Incitative grant from the Ministère de la Jeunesse, de l'Education et de la Recherche (number 022 0528). The authors thank C. Bruand for providing nirK and norD mutant S. meliloti strains and M. Delledonne and P. Frendo for helpful discussions.

\section{LITERATURE CITED}

Baek, S. H., and Shapleigh, J. P. 2005. Expression of nitrite and nitric oxide reductases in free-living and plant-associated Agrobacterium tumefaciens C58 cells. Appl. Environ. Microbiol. 71:4427-4436.

Becana, M., Aparicio-Tejo, P. M., and Sanchez-Diaz, M. 1985. Nitrate and nitrite reduction by alfalfa root nodules: Accumulation of nitrite in Rhizobium meliloti bacteroids and senescence of nodules. Physiol. Plant. 64:353-358.

Bethke, P. C., Badger, M. R., and Jones, R. L. 2004. Apoplastic synthesis of nitric oxide by plant tissues. Plant Cell 16:332-341

Boisson-Dernier, A., Chabaud, M., Garcia, F., Bécard, G., Rosenberg, C., and Barker, D. G. 2001. Agrobacterium rhizogenes-transformed roots of Medicago truncatula for the study of nitrogen-fixing and endomycorrhizal symbiotic associations. Mol. Plant-Microbe Interact. 14:695700 .

Colebatch, G., Desbrosses, G., Ott, T., Krusell, L., Montanari, O., Kloska, J., and Udvardi, M. K. 2004. Global changes in transcription orchestrate metabolic differentiation during symbiotic nitrogen fixation in Lotus japonicus. Plant J. 39:487-512.

Correa-Aragunde, N., Graziano, M., and Lamattina, L. 2004. Nitric oxide plays a central role in determining lateral root development in tomato. Planta 218:900-905.

Crawford, N. M., and Guo, F. Q. 2005. New insights into nitric oxide metabolism and regulatory functions. Trends Plant Sci. 10:195-200.

Cueto, M., Hernandez-Perera, O., Martin, R., Bentura, M. L., Rodrigo, J., Lamas, S., and Golvano, M. P. 1996. Presence of nitric oxide synthase activity in roots and nodules of Lupinus albus. FEBS (Fed. Eur. Biochem. Soc.) Lett. 398:159-164.

Delledonne, M. 2005. NO news is good news for plants. Curr. Opin. Plant Biol. 8:1-7.

Delledonne, M., Xia, Y., Dixon, R. A., and Lamb, C. 1998. Nitric oxide functions as a signal in plant disease resistance. Nature 394:585-588.

Desikan, R., Griffiths, R., Hancock, J., and Neill, S. 2002. A new role for an old enzyme: Nitrate reductase-mediated nitric oxide generation is required for abscissic acid-induced stomatal closure in Arabidopsis thaliana. Proc. Natl. Acad. Sci. U.S.A. 99:16314-16318.

Dordas, C., Hasinoff, B. B., Igamberdiev, A. U., Manac'h, N., Rivoal, J., and Hill, R. D. 2003a. Expression of a stress-induced hemoglobin affects NO levels produced by alfalfa root cultures under hypoxic stress. Plant J. 35:763-770.

Dordas, C., Rivoal, J., and Hill, R. D. 2003b. Plant haemoglobins, nitric oxide and hypoxic stress. Ann. Bot. 91:173-178.

Durner, J., Wendehenne, D., and Klessig, D. F. 1998. Defence gene induction in tobacco by nitric oxide, cyclic GMP and cyclic ADP-ribose. Proc. Natl. Acad. Sci. U.S.A. 95:10328-10333.

Frendo, P., Gallesi, D., Turnbull, R., Van de Sype, G., Hérouart, D., and Puppo, A. 1999. Localisation of glutathione and homoglutathione in Medicago truncatula is correlated to a differential expression of genes involved in their synthesis. Plant J. 17:215-219.

Gabaldon, C., Gomez Ros, L. V., Pedreno, M. A., and Ros Barcelo, A. 2005. Nitric oxide production by the differentiating xylem of Zinnia elegans. New Phytol. 165:121-130.

Gilles-Gonzalez, M. A., and Gonzalez, G. 2005. Heme-based sensors: Defining characteristics, recent developments, and regulatory hypotheses. J. Inorg. Biochem. 99:1-22.

Gow, A. J., Luchsinger, B. P., Pawloski, J. R., Singel, D. J., and Stamler, J. S. 1999. The oxyhemoglobin reaction of nitric oxide. Proc. Natl. Acad. Sci. U.S.A. 96:9027-9032.
Guo, F. Q., Okamoto, M., and Crawford, N. M. 2003. Identification of a plant nitric oxide synthase gene involved in hormonal signaling. Science 302:100-103.

Harutyunyan, E. H., Safonova, T. N., Kuranova, I. P., Popov, A. N., Teplyakov, A. V., Obmolova, G. V., Vainshtein, B. K., Dodson, G. G., and Wilson, J. C. 1996. The binding of carbon monoxide and nitric oxide to leghaemoglobin in comparison with other haemoglobins. J. Mol. Biol. 264:152-161.

Haynes, J. G., Czymmek, K. J., Carlson, C. A., Veereshlingam, H., Dickstein, R., and Sherrier, D. J. 2004. Rapid analysis of legume root nodule development using confocal microscopy. New Phytol. 163:661668.

He, Y., Tang, R. H., Hao, Y., Stevens, R. D., Cook, C. W., Ahn, S. M., Jing, L., Yang, Z., Chen, L., Guo, F., Fiorani, F., Jackson, R. B., Crawford, N. M., and Pei, Z. M. 2004. Nitric oxide represses the Arabidopsis floral transition. Science 305:1968-1971.

Hirsch, A. M., Bang, M., and Ausubel, F. M. 1983. Ultrastructural analysis of ineffective alfalfa nodules formed by nif::Tn5 mutants of Rhizobium meliloti. J. Bacteriol. 155:367-380.

Kato, K., Okamura, Y., Kanahama, K., and Kanayama, Y. 2003. Nitrateindependent expression of plant nitrate reductase in Lotus japonicus root nodules. J. Exp. Bot. 388:1685-1690.

Lohar, D. P., Sharopova, N., Endre, G., Penuela, S., Samac, D., Town, C., Silverstein, K. A. T., and VandenBosch, K. A. 2006. Transcript analysis of early nodulation events in Medicago truncatula. Plant Physiol. 140:221-234.

Mathieu, C., Moreau, S., Frendo, P., Puppo, A., and Davies, M. J. 1998. Direct detection of radicals in intact soybean nodules: Presence of nitric oxide-leghemoglobin complexes. Free Rad. Biol. Med. 24:1242-1249.

Mayer, B., and Hemmens, B. 1997. Biosynthesis and action of nitric oxide in mammalian cells. Trends Biochem. Sci. 22:477-481.

Mesa, S., Bedmar, E. J., Chanfon, A., Hennecke, H., and Fischer, H. M. 2003. Bradyrhizobium japonicum NnrR, a denitrification regulator, expands the FixLJ-FixK 2 regulatory cascade. J. Bacteriol. 185:3978-3982.

Mesa, S., de Dios Alché, J., Bedmar, E. J., and Delgado, M. J. 2004. Expression of nir, nor and nos denitrification genes from Bradyrhizobium japonicum in soybean root nodules. Physiol. Plant. 120:205-211.

Murgia, I., Delledonne, M., and Soave, C. 2002. Nitric oxide mediates iron-induced ferritin accumulation in Arabidopsis. Plant J. 30:521528.

Nakatsubo, N., Kojima, H., Kikuchi, K., Nagoshi, H., Hirata, Y., Maeda, D., Imai, Y., Irimura, T., and Nagano, T. 1998. Direct evidence of nitric oxide production from bovine aortic endothelial cells using new fluorescence indicators: Diaminofluoresceins. FEBS (Fed. Eur. Biochem. Soc.) Lett. 427:263-266.

Neill, S. J., Desikan, R., and Hancock, J. T. 2003. Nitric oxide signaling in plants. New Phytol. 159:11-35.

Otvos, K., Pasternak, T. P., Miskolczi, P., Domoki, M., Dorjgotov, D., Szucs, A., Bottka, S., Dudidts, D., and Feher, A. 2005. Nitric oxide is required for, and promotes auxin-mediated activation of, cell division and embryogenic cell formation but does not influence cell cycle progression in alfalfa cell cultures. Plant J. 43:849-860.

Perazzolli, M., Dominici, P., Romero-Puertas, M.C., Zago, E., Zeier, J., Sonoda, M., Lamb, C., and Delledonne, M. 2004. Arabidopsis nonsymbiotic haemoglobin AHb1 modulates nitric oxide bioactivity. Plant Cell 16:2785-2794.

Planchet, E., Jagadis Gupta, K., Sonoda, M., and Kaiser, W. M. 2005. Nitric oxide emission from tobacco leaves and cell suspensions: Rate limiting factors and evidence for the involvement of a mitochondrial electron transport. Plant J. 41:732-743.

Shimoda, Y., Nagata, M., Suzuki, A., Abe, M., Sato, S., Kato, T., Tabata, S., Higashi, S., and Uchiumi, T. 2005. Symbiotic Rhizobium and nitric oxide induce gene expression of non-symbiotic hemoglobin in Lotus japonicus. Plant Cell Physiol. 46:99-107.

Van Baarlen, P., Staats, M., and Van Kan, J. A. L. 2004. Induction of programmed cell death in lily by the fungal pathogen Botrytis elliptica. Mol. Plant Pathol. 5:559-574.

Vinardell, J. M., Fedorova, E., Cebolla, A., Kevei, Z., Horvath, G., Kelemen, Z., Tarayre, S., Roudier, F., Mergaert, P., Kondorosi, A., and Kondorosi, E. 2003. Endoreduplication mediated by the anaphase-promoting complex CCS52A is required for symbiotic cell differentiation in Medicago truncatula nodules. Plant Cell 15:2093-2105.

Wendehenne, D., Durner, J., and Klessig, D. F. 2004. Nitric oxide: A new player in plant signaling and defence. Curr. Opin. Plant Biol. 7:449455.

Zeidler, D., Zahringer, U., Gerber, I., Dubery, I., Hartung, T., Bors, W., Hutzler, P., and Durner, J. 2004. Innate immunity in Arabidopsis thaliana: Lipopolysaccharides activate nitric oxide synthase (NOS) and induce defence genes. Proc. Natl. Acad. Sci. U.S.A. 101: 15811-15816. 